УДК 7.025 .4

https://doi.org/10.24852/2587-6112.2021.6.302.307

\title{
ОПЫТ РЕСТАВРАЦИИ ЭПИГРАФИЧЕСКИХ ПАМЯТНИКОВ И АРХИТЕКТУРНЫХ ДЕТАЛЕЙ ИЗ ФОНДОВ БГИАМЗ
}

\author{
(C) 2021 г. А.С. Макарова, П.Ю. Каплан, Р.В. Котов, П.В. Федан
}

В работе описывается опыт подготовки к экспонированию памятников из камня из коллекции Болгарского историко-культурного музея-заповедника, насчитывающей более 200 единиц хранения. Среди них - собрание надгробий XIII-XIV вв., декорированных орнаментальной резьбой, надписями, монохромной покраской, а также фрагменты архитектурного декора из известняка, туфового камня и гипса. Памятники относятся к периоду существованию Болгарского улуса в составе Золотой Орды. Значительное количество памятников имеет неудовлетворительную сохранность и нуждается в проведении реставрационно-консервационных работ. Кроме того, в условиях существующей экспозиции, музей не имеет возможности полноценно представить коллекцию. С целью создания условий для экспонирования лапидарных памятников в настоящий момент на базе Болгарского музея-заповедника создается лапидарий. Для сохранения объектов культурного наследия требуются объединённые усилия различных специалистов - реставраторов, хранителей, археологов. Параллельно с разработкой концепции экспозиции и ее пространственно-архитектурного решения проводится цикл реставрационных работ, освещающийся в настоящей статье.

Ключевые слова: археология, реставрация, лапидарий, Золотая орда, памятники из природного камня, эпиграфические памятники, БГИАМЗ.

\section{EXPERIENCE OF THE RESTORATION OF EPIGRAPHIC MONUMENTS AND ARCHITECTURAL DETAILS FROM THE COLLECTION OF BOLGAR STATE HISTORICAL AND ARCHITECTURAL MUSEUM- RESERVE}

\section{A.S. Makarova, P.Yu. Kaplan, R.V. Kotov, P.V. Fedan}

The paper describes the experience of treatment during the preparation of stone objects from the collection of Bolgar State Historical and Architectural Museum-Reserve, which consist of 200 storage units, for museum display. The collection includes gravestones of the $13^{\text {th }}-14^{\text {th }}$ centuries decorated with ornamental carvings, inscriptions, monochrome painting, and fragments of architectural decor made of limestone, tuff and plaster. The objects date back to the period of the Bolgar ulus being part of the Golden Horde. Most of them are in poor condition and require restoration and conservation. Besides, the museum cannot provide a complete display of the collection in the existing exposition conditions. In order to provide the conditions for collection display, a lapidarium is being constructed in the territory of the Bolgar Museum-Reserve. Preservation of cultural heritage sites requires joint efforts by various specialists - conservators, curators, and archaeologists. Along with the development of an exposition concept and its spatial and architectural solutions, a cycle of conservation treatment of the objects is performed, which is described in this paper.

Keywords: archaeology, restoration, lapidarium, Golden Horde, natural stone objects, epigraphic monuments, Bolgar State Historical and Architectural Museum-Reserve.

Лапидарная коллекция Болгарского историко-культурного музея-заповедника насчитывает более 200 единиц хранения. Среди них фрагменты архитектурного декора и малых архитектурных форм, мемориальной пластики, строительного камня и прочие находки. Основным материалом изготовления служил различного вида известняк местного происхождения, а также в некоторых случаях туф, песчаник, гипс (Айдаров, 2001; Мухаметшин, 2014). Большая часть находок была выявлена в ходе реставрационных и ремонтных работ на архитектурных памятниках и церкви Успения Пресвятой Богородицы. Ядром коллекции является собрание надгробных стел, часть из которых декорирована орнаментальной резьбой, рельефными надписями, монохромной покраской. Средневековые эпитафии из болгарского собрания представляют бесспорный научный интерес и ранее неоднократно публиковались (Малахов, 1947; Юсупов, 1953; Калинин, 1956; Булатов, 1963; Мухаметшин, 2008; Мухаметшин, 2014). Самые яркие и наиболее сохранные из них представлены в 
экспозиции Северного мавзолея. Среди них эпитафии Илчи Имел, Шамар Малики, Алп ходжи, Хасана Самарканди и другие, датируемые концом XIII - началом XIV вв. (Мирас, 2016). Некоторые памятники коллекции также выставлены в Ханской усыпальнице. Некоторые находки органично включены в постоянную экспозицию музея и служат яркими акцентами в повествовании о многообразии историко-культурного и духовного наследия татарского народа.

Несмотря на публикации отдельных памятников, большая часть коллекции остается малодоступной для исследователей и посетителей по нескольким причинам. Все памятники требуют приведения в экспозиционный вид, некоторые нуждаются в полноценной и технологически сложной реставрации. А имеющиеся выставочные площади не позволяют разместить многочисленные, часто массивные объекты в сложившемся экспозиционном комплексе музея.

Вопрос сохранности коллекции и возможности еe экспонирования поднимался в разные годы. Не случайно П.Е. Корнилов, Г.В. Юсупов, Н.Ф. Калинин неоднократно обращали внимание на проблематику обеспечения сохранения памятников лапидарной коллекции (Корнилов, 1929; Мухаметшин, 2014, с. 167).

Продолжительное время существовала практика экспонирования предметов под открытым небом. Изготовленные из известняка памятники в результате нахождения в атмосферных условиях подвергались отрицательному воздействию природы и человека. Памятники разрушались в результате процессов выветривания, биообрастания, повреждались из-за вандальных действий. Нельзя не отметить ряд усилий, предпринимавшихся в этот период для обеспечения их сохранности. В качестве превентивных мер сооружались ограждения и навесы. Однако помимо этих бесспорно эффективных мер применялись и другие решения, к примеру, покрытие поверхности побелкой или краской (Мухаметшин, 2014).

В настоящий момент эпиграфические и прочие каменные памятники экспонируются в более щадящих условиях: в экспозиции музея с действующей системой температурно-влажностного режима, а также в неотапливаемых помещениях Северного мавзолея и Ханской усыпальницы. Последний способ экспонирования менее удачен, так как не решает проблему солевого разрушения предметов. Хранение каменных предметов организовано преимущественно под открытым небом, от осадков они защищены навесом.

Осуществлялись и работы по реставрации отдельных надгробий, как усилиями приглашенных специалистов, так и силами сотрудников музея-заповедника. Так, в 2014 г. памятники, находящиеся в Северном мавзолее, прошли консервацию, которую выполнили сотрудники ВХНРЦ им. И.Э. Грабаря под руководством Д.Е. Котова. Ввиду сжатых сроков удалось выполнить только расчистку поверхности надгробных стел, повторную мастиковку швов и утрат с последующей тонировкой. Однако уже тогда были заметны процессы солевого разрушения памятников, приобретающие опасный характер в настоящее время.

Кроме того, к реставрации ряда надгробий привлекались сотрудники музея-заповедника. На основании устных свидетельств удается частично реконструировать методику этих работ. Для склейки фрагментов применялся преимущественно строительный плиточный клей, для мастиковки швов склейки - белый цемент. Удаление загрязнений перед склейкой выполнялось при помощи водной расчистки (промывки). Указанная методика не в полной мере соответствует текущей реставрационной практике.

Таким образом, собрание лапидарной коллекции Болгарского музея-заповедника в настоящий момент представлено фрагментарно, многие из памятников, представляющих большую историко-культурную ценность, не экспонируются из-за состояния сохранности и отсутствия выставочных площадей.

Н.Ф. Калинин решение данной проблемы видел в создании лапидария (Мухаметшин, 2014, с. 167). Следует отметить, что именно создание лапидария - здания (помещения) для экспонирования коллекций каменных памятников - представляется наиболее перспективным способом демонстрации больших собраний. В музеях Российской Федерации концепция лапидария как отдельно стоящей постройки, в которой представлены каменные археологические находки, 
реализована, к сожалению, в редких учреждениях. На наш взгляд, наиболее интересно лапидарий устроен в Восточно-Крымском историко-культурном музее-заповеднике (г. Керчь), где сформированы четыре экспозиции, полностью основанные на информационном потенциале памятников из камня. В настоящий момент разрабатывается экспозиция и архитектурное решение лапидария в Центральном музее древнерусской истории и культуры имени Андрея Рублева. Таким образом, идея создания лапидария кажется наиболее перспективной с точки зрения раскрытия историко-культурной ценности находок, а также долгосрочного обеспечения их сохранности.

Для достижения этих целей на территории Болгарского городища в 2018 году был возведен лапидарий. В настоящий момент в здании продолжаются ремонтные работы, параллельно с которыми разрабатывается концепция экспозиции. Одновременно с этим процессом в 2019 г. по инициативе музея-заповедника Институт археологии им. А.Х. Халикова

АН РТ совместно с Казанским (Приволжским) федеральным университетом (КФУ) начал консервационно-реставрационные работы на памятниках, которые должны войти в экспозицию строящегося лапидария. За два года консервацию и реставрацию прошел 41 предмет - 14 эпиграфических памятников и 27 архитектурных деталей, большинство из них выполнено из известняка.

Большая часть эпитафий и архитектурных каменных деталей на момент поступления в реставрацию имела неудовлетворительную сохранность и утратила экспозиционный вид. На сохранность каменных памятников влияло множество факторов. Это и сложная история их бытования, и условия археологизации, и условия их последующего хранения. Так, к основным видам разрушений данных предметов можно отнести:

биологические повреждения (лишайники, водоросли, микроскопические грибы);

механические повреждения (утраты, сколы, царапины);

солевое разрушение (кристаллизация водорастворимых солей, приводящая к мелению, шелушению поверхности, отслоению частиц);

локальные трещины и отслоения; разнородные загрязнения, образовавшиеся как от контакта с почвой, так и в результате соприкосновения с другими предметами;

\section{непрофессиональную реставрацию.}

На реставрационном совете Института археологии АН РТ было сформулировано следующее обобщенное реставрационное задание, которое уточнялось в зависимости от сохранности отдельных экспонатов:

очистка поверхности от разного рода загрязнений;

проведение микрохимического анализа на наличие сульфатсодержащих и хлорсодержащих солей в структуре камня с последующим обессоливанием памятника;

обработка от биообрастаний и следов их жизнедеятельности;

локальное структурное укрепление;

склейка фрагментированных памятников с последующей мастиковкой утрат.

В обязательном порядке каждый предмет проходил предреставрационные лабораторные исследования - качественный микрохимический анализ на наличие водорастворимых солей. В трети случаев наличие солей выявлено не было. Остальные две трети содержали сульфаты (41\% памятников) и хлориды (28\% памятников).

Работы производились под руководством аттестованного художника-реставратора произведений из камня и гипса, ученого секретаря ФГБНИУ «Государственный научно-исследовательский институт реставрации» А.С. Макаровой. Реставрация проводилась в два этапа. В 2019 г. в рамках двухнедельной студенческой практики-интенсива были проведены предреставрационные исследования и комплекс консервационно-реставрационных мероприятий на 7 объектах - трех архитектурных деталях и четырех эпиграфических памятниках. Реставрационные работы в рамках проекта по созданию лапидария стали удачной попыткой совмещения волонтерского опыта магистров профиля «Реставрация историко-культурного наследия» КФУ с привлечением реставраторов Института археологии им. А.Х. Халикова.

Продолжение реставрации началось осенью 2020 г., когда в реставрацию были переданы еще 34 памятника. Было решено не осуществлять транспортировку памятников за пределы Болгара и провести реставрацию 
на археологической базе и для крупногабаритных памятников, не подлежащих транспортировке, в помещениях фондов БГИАМЗ.

На эпиграфических памятниках были проведены следующие консервационнореставрационные мероприятия:

Сухая очистка поверхности.

Промывка поверхности с использованием неионогенных ПАВ.

Расчистка поверхности пароструйным аппаратом для удаления стойких почвенных загрязнений, локализованных в кавернах и порах камня.

Химическая очистка: удаление музейного шифра.

Обессоливание методом наложения пульпы.

Биоцидная обработка с использованием 5\% раствора «Катамин АБ» («Катамин АБ» - 50 г, изопропиловый спирт - 500 г, дистиллированная вода -450 г).

Склейка фрагментов с установкой пиронов (при необходимости).

Локальное укрепление расслоений.

Мастиковка швов.

Нанесение обратимой подложки для инвентарного номера.

Особый интерес представлял эпиграфический памятник с красочным слоем, фрагментарно сохранившимся на внешней стороне. Красочный слой аккуратно очищался туго отжатыми ватными тампонами, смоченными в дистиллированной воде. После расчистки участки с красочным слоем укреплялись $3 \%$ раствором полимерного клея ПВБ (поливинилбутираль) для предотвращения осыпей.

Еще одним интересным памятником с точки зрения реставрации стала эпитафия Хаммада. На ее внешней стороне присутствовало вандальное граффити, процарапанное острым предметом. Граффити было расположено на бросающемся в глаза участке и имело крайне небольшую глубину. Для маскировки граффити были опробованы несколько методов. Наиболее эффективной оказалась мастиковка акриловым грунтом с последующей тонировкой.

Также две эпитафии были ранее реставрированы: это эпитафия 702 г. х., опубликованная в монографии «Мирас - Наследие», для скрепления фрагментов которой использовался, вероятнее всего, плиточный клей, и эпита- фия Хаджи, где для соединения двух фрагментов были использованы пироны без клеящих веществ, о чем свидетельствуют отверстия в обоих фрагментах памятника без каких-либо следов клея.

Еще один памятник, реставрация которого представляла определенные сложности - это эпитафия Гали. Она состоит из восьми массивных фрагментов. Общая длина надгробия составляет почти 2,5 метра. Этот памятник по решению реставрационного совета был склеен частично с установкой пиронов. Завершение склейки и докомпоновка утрат будут выполняться непосредственно в помещении лапидария. В противном случае транспортировка надгробия и его установка представляются невозможными.

При реставрационных работах на архитектурных деталях упор был сделан на удаление из структуры водорастворимых солей и укрепление расслоений (Агеева, 2003; Антонян, 2006; Макарова, 2018). Укрепление небольших трещин проводилось подведением консолидирующего раствора полимера (ПВБ - 3\% раствор в этиловом спирте). В случае массивных отслоений и значительных областей осыпей использовался кремнийорганический состав «KSE-100» фирмы «Remmers». В ряде случаев вдоль расслоений после их укрепления выполнялись отбортовки. В качестве докомпоновочного раствора использовался минеральный камнезаменитель фирмы «Remmers».

Дальнейшее экспонирование памятников планируется на специальных постаментах, художественное решение которых зависит от архитектурной концепции создаваемого лапидария.

Таким образом, для создания Болгарского лапидария выполнена реставрация большого числа памятников, которые планируется включить в будущую экспозицию. Реализация данного проекта показала, что привлечение студентов профильных направлений подготовки к реставрации археологического камня может быть перспективным. При этом необходимо обеспечить научное руководство реставрационными работами и подобрать объекты средней сложности. Также интересным опытом стало решение отложить завершение реставрации некоторых памятников до монтажа экспозиции. 
В условиях экспозиции планируется завер- ков, а также уточнить тонировки исходя из шить склейку наиболее массивных памятни- условий освещенности.

\section{ЛИТЕРАТУРА}

Агеева Э.И. Консервация и реставрация скульптуры из камня. Учебное пособие. М.: РГГУ, 2003. 81 с.

Айдаров С.С. Исследование и реставрация памятников монументального зодчества Болгара // Город Болгар. Монументальное строительство, архитектура, благоустройство / Отв. ред. Г.А. Федоров-Давыдов. М.: Наука, 2001. С. 5-150.

Антонян А.С. Реставрация скульптуры из камня. Методические рекомендации. М.: СканРус, 2006. $100 \mathrm{c}$.

Булатов А.Б. Булгарские эпиграфические памятники XIII-XIV вв. Правобережье Волги // Эпиграфика Востока. 1963. T. XVI. С. 56-71.

Волга от истока до Каспия: путеводитель на 3 языках: рус., фр. и нем. М.: т-во скоропеч. А.А. Левенсон, ценз. 1903. 96, XXXI с.; 12x20

Калинин Н.Ф. Булгаро-татарские эпиграфические памятники как исторический источник // Тезисы докладов на конференции по археологии, древней и средневековой истории народов Поволжья в Казани в 1956 г. / Ред. А. П. Смирнов, Н. Я. Мерперт. М.: ИИМК, 1956. С. 25-31.

Корнилов П.Е. К изучению эпиграфического резного камня болгаро-татарской эпохи // МОРРП ТАССР. Казань, 1929. Вып. 3. С. 1-10.

Макарова А.С. Полевая консервация археологических находок из камня, к вопросу о методической обеспеченности // Журнал Института наследия 2018. №1 (12). URL: http://nasledie-journal.ru/ru/ journals/179.html (дата обращения: 30.03.2021).

Малов С.E. Булгарские и татарские эпиграфические памятники// Эпиграфика Востока. 1947. Т. I. C. 38-45.

МИРАС-НАСЛЕДИЕ. Том 1. Татарстан - Крым. Город Болгар и изучение татарской культуры в Татарстане и в Крыму в 1923-1929 годах: в 3-х томах / сост. и отв. ред. С.Г. Бочаров, А.Г. Ситдиков. Казань: ООО «Астер Плюс», 2016. 580 с.

Мухаметиин Д.Г., Хакимзянов Ф.С. Эпиграфические памятники города Булгара. Казань: Таткнигоиздат, $1987.128 \mathrm{c}$.

Мухаметшин Д.Г. Татарские эпиграфические памятники. Региональные особенности и этнокультурные варианты / Археология евразийских степей. Вып. 6. Казань: Институт археологии АН РТ, 2008. 132 с. Илл.

Мухаметшин Д.Г. Г.В. Юсупов и проблемы татарской эпиграфики // Поволжская археология. 2014. №4 (10). С. 154-177.

Юсупов Г.В. О некоторых булгарских эпиграфических памятниках// Эпиграфика Востока. 1953. T. VII. C. $26-30$.

\section{Информация об авторах:}

Макарова Анастасия Сергеевна, художник-реставратор 2-ой категории. Ученый секретарь. Государственный научно-исследовательский институт реставрации (г. Москва, Россия). Старший преподаватель. Российский государственный гуманитарный университет (г. Москва, Россия); aanpilogova@mail.ru

Каплан Полина Юрьевна, научный сотрудник, Институт археологии им. А.Х. Халикова АН РТ, преподаватель кафедры реставрации наследия (на базе АО ТСНРУ), Казанский (Приволжский) Федеральный университет (г. Казань); kapolina15@gmail.com

Котов Роман Владимирович, лаборант-исследователь,Институт археологии им. А.Х. Халикова АН РТ (г. Казань, Россия); brodiagastar@yandex.ru

Федан Павел Владимирович, научный сотрудник, Институт археологии им. А.Х. Халикова АН РТ, преподаватель кафедры реставрации наследия (на базе АО ТСНРУ), Казанский (Приволжский) Федеральный университет (г. Казань); pavel.fedan@mail.ru

\section{REFERENCES}

Ageeva, E. I. 2003. Konservtsiia i restavratsiia skul'ptury iz kamnia (Conservation and Restoration of Stone Sculptures). Moscow: Russian University for the Humanities (in Russian). 
Aidarov, S. S. 2001. In Fedorov-Davydov, G. A. (ed.). Gorod Bolgar. Monumental'noe stroitel stvo, arkhitektura, blagoustroistvo (City of Bolgar. Monumental Building, Architecture, Improvement). Moscow: "Nauka" Publ., 5-150 (in Russian).

Antonyan, A. S. 2006. Restavratsiia skul'ptury iz kamnia. Metodicheskie rekomendatsii (Restoration of Stone Sculptures. Methodological Recommendations). Moscow: "SkanRus" Publ. (in Russian).

Bulatov, A. B. 1963. In Epigrafika Vostoka (Oriental Eipgraphy) XVI, 56-71 (in Russian).

1903. Volga ot istoka do Kaspiia: putevoditel'na 3 iazukakh (Volga from the Source to the Caspian: Travel Guide in 3 Languages). Moscow: "Tovarishchestvo skoropechati A.A. Levenson" Publ. (in Russian).

Kalinin, N. F. 1956. In Smirnov, A. P., Merpert, N. Ya. (eds.). Tezisy dokladov na konferentsii po arkheologii, drevnei i srednevekovoi istorii narodov Povolzh'ia v Kazani v $1956 \mathrm{~g}$. (Abstracts of Reports of the Conference on the Archaeology, Ancient and Medieval History of the Peoples of the Volga Region Held in Kazan in 1956). Moscow, 25-31 (in Russian).

Kornilov, P.E. 1929. In Materialy po okhrane, remontu i restavratsii pamiatnikov TASSR (Materials on the Protection, Repair and Restoration of Monuments in TASSR) 3. Kazan, 1-10 (in Russian).

Makarova, A. S. 2018. In Zhurnal Istituta naslediia (The Heritage Institute Journal) 12 (1). Available at: http://nasledie-journal.ru/ru/journals/179.html (accessed 30.03.2021).

Malov, S. E. 1947. In Epigrafika Vostoka (Oriental Eipgraphy) I, $38-45$ (in Russian).

Bocharov, S. G., Sitdikov, A.G. (eds.). 2016. MIRAS-NASLEDIE. Tatarstan - Krym. Gorod Bolgar $i$ izuchenie tatarskoj kul'tury v Tatarstane $i$ v Krymu v 1923-1929 godah: v 3-kh tomah (MIRAS-NASLEDIE. Tatarstan and Crimea. The City of Bolgar and the study of Tatar culture in Tatarstan and the Crimea in 1923-1929: in 3 volumes) 1. Kazan: "Aster Plyus" Publ. (in Russian).

Mukhametshin, D. G. 2008. Tatarskie epigraficheskie pamiatniki. Regional'nye osobennosti i etnokul'turnye varianty (Tatar epigraphic sites. Regional features and ethnic-cultural versions) Series: Arkheologiia evraziiskikh stepei (Archaeology of the Eurasian Steppes) 6. Kazan: Institute of History, Academy of Sciences of the Republic of Tatarstan (in Russian).

Mukhametshin, D. G. 2014 In Povolzhskaia arkheologiia (Volga River Region Archaeology) 10 (4), 154-177 (in Russian).

Mukhametshin, D. G., Khakimzyanov, F. S. 1987. Epigraficheskie pamiatniki goroda Bulgara (Epigraphic Monuments of Bolgar City). Kazan: "Tatknigoizdat" Publ. (in Russian).

Yusupov, G. V. 1953. In Epigrafika Vostoka (Oriental Eipgraphy) VII, 26-30 (in Russian).

\section{About the Authors:}

Makarova Anastasia S., conservator of the 2nd category. Academic secretary. The State Research Institute for Conservation. Gastello St., 44, Moscow, 107014, Russian Federation; Russian State University For Humanities. Miusskaya Sq., 6, Moscow, 125993, Russian Federation; aanpilogova@mail.ru

Kaplan Polina Yu. Institute of Archaeology named after A. Kh. Khalikov, Tatarstan Academy of Sciences. Butlerov Str., 30, Kazan, 420012, the Republic of Tatarstan, Russian Federation; Kazan (Volga Region) Federal University. Kremlyovskaya str., 18, Kazan, 420008, the Republic of Tatarstan, Russian Federation; kapolina15@gmail.com

Kotov Roman V. Institute of Archaeology named after A. Kh. Khalikov, Tatarstan Academy of Sciences. Butlerov Str., 30, Kazan, 420012, the Republic of Tatarstan, Russian Federation; brodiagastar@yandex.ru

Fedan Pavel V. Institute of Archaeology named after A. Kh. Khalikov, Tatarstan Academy of Sciences. Butlerov Str., 30, Kazan, 420012, the Republic of Tatarstan, Russian Federation; Kazan (Volga Region) Federal University. Kremlyovskaya str., 18, Kazan, 420008, the Republic of Tatarstan, Russian Federation; pavel. fedan@mail.ru

Статья поступила в журнал 01.10.2021 г. Статья принята к публикации 01.12.2021 г. Авторы внесли равноценный вклад в работу. 